\title{
The performance of relational ties: A functional approach in the biotechnology industry
}

\author{
D.W. $\mathrm{Ng}^{1}$, J. Unterschultz ${ }^{2}$ and E. Laate ${ }^{2}$ \\ ${ }^{1}$ Texas A\&M University, Department of Agricultural Economics, 349 B Blocker Building, College Station, Texas 77843, USA, \\ dng@ag.tamu.edu \\ ${ }^{2}$ University of Alberta, Department of Rural Economy, Canada
}

\begin{abstract}
Understanding the performance of social networks has attracted the attention of contemporary management research. The performance of a firm's strength of social ties has been the subject of considerable debate. On the one hand, strong ties draw on redundant and close partner experiences to increase a firm's specialization. On the other hand, weak ties gain access to non-redundant ideas, resources and opportunities to increase a firm's flexibility to market opportunities. Strong and weak ties have, thus, been depicted as opposing influences to a firm's performance. This study, however, offers an alternative explanation to this strong and weak tie debate. In this study, a theoretical and empirical examination of strong and weak tie performance is conducted in the biotechnology industry. This study finds strong and weak ties exhibit distinct knowledge sharing and commercializing functions that positively impact a biotechnology firm's performance. By incorporating the distinctive functions of strong and weak ties, a firm's tie strength does not exert opposing influences to performance. In addition, due to their distinctive functions, strong and weak ties exhibit diminishing return effects. This suggests a firm can develop a network structure that maximizes its ability to develop its research knowledge and capitalize on commercializing opportunities. The contributions and implications of this study are also discussed.
\end{abstract}

Keywords: tie strength, performance, biotechnology

\section{Introduction}

Interest in social networks has increasingly drawn the attention of scholars and practitioners of management (Brass et al., 2004). Unlike the atomistic and self-interested behaviors of economic agents, social networks emphasize inter-agent relationships as sources of strategic opportunity and constraint (Brass et al., 2004). A central proposition of social networks is: firms with "better" connected networks have a competitive advantage over firms with less connected networks (Brass et al. 2004; Gargiulo and Benassi, 2000). However, debate continues on what it means to be "better" connected and how such "better" connections can impact firm performance (Brass et al., 2004; Ng, 2004, 2005; Rowley et al., 2000; Sporleder and Moss, 2002).

For instance, the performance of structural holes and closed networks has been significantly debated in sociology research (e.g. Burt, 2000). Structural holes occur when a firm is directly connected to different members that are not connected to each other (Burt, 1992). Structural holes provide a firm access to new and timely information and opportunities to broker information from disparate regions of a network (Burt, 1992, 2000). A firm can also be connected through closed networks. With closed networks, a firm is directly connected to members that are connected to each other (Coleman, 1988). As the firm is directly and indirectly connected to members of a closed network, a closed network transmits highly redundant information. This promotes a firm's conformance to social norms and a firm's specialization and coordination of tasks (Coleman, 1988). Structural holes, thereby, favor the diversity benefits of non-redundant information, while closed networks favor the specialization benefits of redundant information. Although the performance of structural holes and closed networks remains highly debated ${ }^{1}$, Brass et al. (2004), Granovetter (1983, 1985), and Uzzi (1997) contend the performance of a firm's relational ties has also been the subject of central debate. As an antecedent to the concepts of structural holes and closed networks (see Burt, 1997), relational ties vary in their frequency, closeness and reciprocity of social exchange (Granovetter, 1983). Relational ties consist of strong and weak ties (Granovetter, $1983,1985)$. Weak ties are highly correlated to the diversity benefits of structural holes (Burt, 2000) because weak ties "bridge" a firm to different regions of a social network which expose a firm to diverse information, opportunities, resources, and ideas (Granovetter, 1983; Perry-Smith and

1 Readers interested in the performance debate of structural holes and closed network should consult Burt (2000). 
Shalley, 2003; Powell et al., 1996; Uzzi, 1997). However, weak ties lack the closeness and reciprocity of strong ties. Through close and reciprocal social exchanges, strong ties transfer detailed and tacit knowledge, develop trust, and promote joint problem solving activities (Granovetter, 1983; Uzzi, 1997). Therefore, similar to closed networks, strong ties provide a firm access to redundant knowledge which increases a firm's specialization. For instance, strong ties promote the development of a critical mass of knowledge expertise (McFadyen and Cannella, 2004; Rowley et al., 2000). Yet, as strong ties connect a firm to highly redundant information, the firm is insulated from the new ideas and resources of weak ties (Brass et al., 2004; Gargiulo and Benassi, 2000). Thus, although strong ties enrich a firm's knowledge and specialized expertise, such gains are made at the expense of reducing a firm's flexibility to new and diverse information (Uzzi, 1997). This has been described as the "paradox of embeddedness" in which Uzzi (1997) notes, "the same processes by which embeddedness [strength of ties] creates a requisite fit with the current environment can paradoxically reduce an organization's ability to adapt."(p. 57).

Although the competing performance of strong and weak ties has received significant attention and debate by network researchers (e.g. Gargiulo and Benassi, 2000; Granovetter 1983; Jones et al., 1997; Kraatz, 1998; PerrySmith and Shalley, 2003; Rowley et al., 2000), this debate, is, however, predicated on a problematic assumption that such ties have oppositional influences to a firm's performance (e.g. Oh et al., 2004; Reagans and Zuckerman, 2001). For instance and consistent with the functional approach of Osborn and Hagedoorn (1997), Uzzi's (1996, 1997) study of the New York apparel industry finds strong and weak ties can exhibit distinct functions that jointly improve a firm's performance. Furthermore, in alliance studies of the biotechnology industry, researchers (Chan et al. 1997; Powell et al., 1996; Rothaermel, 2001; Rothaermel and Deeds, 2004, Teece, 2000) find biotechnology firms form alliances because they exhibit distinct functions in gaining access to scientific knowledge (i.e. R\&D alliances) and to commercializing resources (i.e. production, distribution, marketing etc) in bringing a firm's basic research to market. As functional explanations have been increasingly called for in social network research (Osborn and Hagedoorn, 1997), this study examines the functional distinctions of strong and weak ties in the biotechnology industry. This study contends strong and weak ties not only vary in their tie strength, but as a consequence yield distinct knowledge sharing and commercializing functions. By recognizing their distinctive functions, strong and weak ties do not exert opposing influences to a firm's performance. This offers an alternative explanation to the strong and weak tie debate. This study also shows tie strength performance is subject to diminishing return effects. Various studies on tie strength performance have posited and / or found a linear relationship to firm performance (McEvily and Zaheer, 1999; Perry-Smith and Shalley, 2003; Rowley et al., 2000). Such diminishing effects, therefore, provides a more complex view of tie strength performance. Namely, this study contends differences in a strong and weak ties' knowledge sharing and commercializing functions can give rise to network governance problems that reduce tie strength performance.

This study's objective is, thus, to develop a theoretical and empirical examination of the positive yet diminishing return effects of strong and weak ties in the biotechnology industry. This study offers three contributions. First, strong and weak ties are not only distinguished by differences in their degree of reciprocity and closeness (e.g. Granovetter, 1983), but as a consequence yield distinct knowledge sharing and commercializing functions. These functions in turn yield performance advantages not typically considered in strong and weak tie research (e.g. Gargiulo and Benassi, 2000; Granovetter, 1983; Kraatz, 1998; McFadyen and Cannella, 2004; Perry-Smith and Shalley, 2003; Rowley et al., 2000). Second, this study provides a theoretical and empirical examination of a tie strength's diminishing return effects. This extends the linear performance relationships found in strong and weak tie performance research (McEvily and Zaheer, 1999; Perry-Smith and Shalley, 2003; Rowley et al., 2000). Third, in subscribing to Uzzi's (1997) paradox of embeddedness, this study finds a "balance" of both strong and weak ties results in a network structure that maximizes a biotechnology firm's knowledge and commercialization opportunities.

This study is organized as follows. As the concept of social networks and strategic alliances are highly interrelated, a discussion of strategic alliances and a background of the biotechnology industry are given. This is followed by a discussion of tie strength research. Strong and weak tie hypotheses are then developed for the biotechnology industry. Next, the data and methods are discussed. The results from Weighted Least Squares (WLS) regressions on a sample of 241 North American biotechnology firms are, then, examined. Lastly, the contributions and implications of this study are discussed.

\section{Research background}

\section{Overview of the biotechnology industry}

The growth of the biotechnology industry has been attributed to advances in basic research in recombinant DNA or "rDNA," protein engineering and monoclonal 
antibody or "Mabs" technology (Liebeskind et al., 1996). Such advances in basic research led to a rapid growth of human therapeutics and agricultural biotechnology based products and services (Liebeskind et al., 1996; Sporleder and Moss, 2002). Thus, a biotechnology firm is defined as "firms involved in the research, development, and commercialization of such processes [rDNA, protein engineering Mabs] and products" (Liebeskind et al., 1996: 428). This includes pharmaceutical and agro-biotechnology firms, such as Eli Lilly, Genentech, Monsanto, Biogen, etc. However, as few firms are fully integrated across basic research and commercialization (Pisano, 1990), these research and commercializing functions are coordinated through strategic alliances, such as licensing, marketing, distributions, research, development, collaborative agreements, jointventures, and various forms of equity alliances (Chan $e t$ al., 1997; Deeds and Hill, 1996; Liebeskind et al. 1996; Powell et al., 1996; Rothaermel, 2001; Rothaermel and Deeds, 2004).

\section{Strategic alliances in the biotechnology industry}

As the development of basic research and its commercialization are key requisites to a biotechnology firm's success, researchers have found significant growth in research and commercial based alliances (Chan et al., 1997; Deeds and Hill, 1996; Powell et al., 1996). More broadly speaking, strategic alliances are defined as:

"... as any voluntarily initiated cooperative agreement between firms that involves exchange, sharing, or co-development, and it can include contributions by partners of capital, technology, or firm specific assets" (Rowley et al., 2000: 370).

Alliances pool inter-firm resources to increase a firm's specialization and access to external complementary assets and reduce a firm's exposure to risk (Chan et al., 1997; Rothaermel, 2001). For instance, entrance into the biotechnology industry is prohibitively expensive with R\&D investments averaging $\$ 100-\$ 300$ million / product (Powell et al. 1996). As few biotechnology firms have the financial resources to bring its basic research to market (Pisano, 1990; Rothaermel, 2001), firms form strategic alliances to pool inter-firm resources so as to reduce costly R\&D investments (Chan et al., 1997; Rothaermel, 2001). Furthermore, to advance the commercial development of research prototypes and drug candidates, biotechnology firms require commercializing resources in marketing, distribution, and manufacturing (Teece, 2000). For instance, Deed and Hill (1996), Rothaermel (2001), and Rothaermel and Deeds (2004), observed biotechnology firms form alliances to gain access to external research expertise and to gain access to the commercial resources of established biotechnology firms. In addition, due to the heightened technological risk, uncertainty in FDA regulations and compressed drug development times (Liebeskind et al., 1996; Pisano, 1990), strategic alliances also reduce the risk of R\&D investments and promote a firm's flexibility and speed of product development (Rothaermel and Deeds, 2004).

\section{Conceptual developments: Positive yet diminishing effects of tie strength}

In drawing on a contingency approach to social network research (e.g. Rowley et al., 2000), this study contends strong and weak ties in the biotechnology industry not only vary in their tie strength, but as a consequence yield distinct knowledge sharing and commercializing functions. Due to such distinctive functions, both strong and weak ties yield positive yet diminishing effects to a firm's performance.

\section{Strong tie performance}

Specifically, strong ties consist of frequent and reciprocal social relationships to actors sharing similar beliefs and experiences (Granovetter, 1983). Since strong ties consist of a high frequency of close and reciprocal social exchanges, strong ties promote: (1) the exchange of tacit or difficult to codify knowledge (Dyer and Nobeoka, 2000; Kraatz, 1998; Uzzi, 1997), (2) facilitate joint problem-solving activities (Uzzi, 1997), and (3) the mutual identification of parties promotes trust-based governance (Dyer and Nobeoka, 2000; Granovetter, 1983; Kraatz, 1998; Rowley et al., 2000; Uzzi, 1997).

For instance, Dyer and Nobeoka (2000), Kraatz (1998) and Uzzi (1997) find strong ties develop a greater exchange of detailed and tacit knowledge. The close and repeated exchange of strong ties allow for the transfer of complex and difficult to codify knowledge. Since value generation in the biotechnology industry is derived from the basic and often tacit dimensions of scientific knowledge (Pisano, 1990), the frequent exchange of detailed and tacit scientific knowledge promotes a "critical mass" of knowledge expertise (McFadyen and Cannella, 2004). For instance, McFadyen and Cannella (2004) find biotechnology scientists with strong interpersonal ties positively increased scientific knowledge creation.

As tacit knowledge is shared among strong tie partners, strong ties also promote a firm and its' partner's "joint problem-solving" (Uzzi, 1997) abilities. For instance, absorptive capacity (e.g. Cohen and Levinthal, 1990; Lane and Lubatkin, 1998) research finds the transfer of interfirm knowledge is dependent on a firm having some prior knowledge that is basic or fundamental to its partner's knowledge (Lane and Lubatkin, 1998). Basic knowledge 
consists of the "general understanding of the traditions and techniques upon which a discipline is based" (Lane and Lubatkin, 1998:464). Hence, a firm involved in research programs; such as cancer therapies, protein engineering, medical diagnostics, screening for molecular compounds, etc is better able to relate to partners that share similar research programs. Since strong ties connect a firm to partners with similar knowledge experiences, this similarity in basic knowledge facilitates the sharing of basic research. As basic research is shared among partnering firms, this promotes their joint solving activities in resolving the technical uncertainties of biotechnology research and the discovery of successful drug candidates. Therefore, as strong ties link a firm to common research experiences, this not only increases the firms' joint problem solving abilities, but increases in their subsequent knowledge promotes the further sharing of tacit knowledge experiences.

In addition, as strong ties develop a mutual identification of connected partners and promotes joint problem solving activities, strong ties develop trust-based governance (Granovetter, 1983; Pisano, 1990; Uzzi, 1997). The reciprocal nature of strong ties generates trust among partners (Uzzi, 1997). Trust is important in the biotechnology industry because biotechnology contractual terms are often incomplete (Pisano, 1990). Through the development of trust, strong ties relinquish the need to write complete contracts (see also Jones et al., 1997) that could hamper efforts to share research.

As the development of basic biotechnology research is a fundamental requisite to a firm's performance, the knowledge sharing function of strong ties should positively impact a firm's performance. However, strong ties should also exhibit diminishing return effects. Extensive reliance on strong ties generates competency traps that lead to suboptimal outcomes (Gargiulo and Benassi, 2000; Granovetter, 1973; Jones et al., 1997; Uzzi, 1997). Specifically, through their knowledge sharing function, strong ties lead to increasingly redundant knowledge experiences. This insulates the firm from new insights that are necessary for the development of fundamental technological breakthroughs (Pisano, 1990; Uzzi, 1997). In addition, as strong ties promote the reciprocal exchange and sharing of tacit research knowledge, strong ties can lead to greater investments in co-specialized technologies. For instance, strong ties, such as collaborative or cooperative (non-equity) and $\mathrm{R} \& \mathrm{D}$ agreements, involve resource commitments to co-specialized technologies (Rowley et al., 2000). As strong ties require greater commitments to co-specialized technologies, investments in transaction-specific assets can expose a partner to opportunistic behaviors of "hold up". For instance, Pisano (1990) finds investments from $\mathrm{R} \& \mathrm{D}$ alliances lead to higher co-asset specificity to which leads to problems of hold-up. Hence, although strong ties promote trust and the sharing of tacit research knowledge, a firm's "trustworthiness" can be taken advantaged of. As Granovetter notes, "the more complete the trust, the greater the potential gain for malfeasance" (1985: 491). As a result, an increasing reliance on strong ties exposes a firm to network governance problems of hold up (e.g. Jones et al., 1997) which can eventually reduce a strong tie's performance. Since, strong ties have been associated with research and development, (Deeds and Hill, 1996; Powell et al., 1996; Rowley et al., 2000; Rothaermel and Deeds, 2004), collaborative research (Rothaermel and Deeds, 2004; Rowley et al., 2000), joint-ventures (Rothaermel and Deeds, 2004; Rowley et al., 2000), and equity based alliances (Osborn and Hagedoorn, 1997; Pisano, 1990; Rowley et al., 2000; Uzzi, 1997) - that involve close and reciprocal exchanges -, the following is hypothesized:

Hypothesis 1: Strong ties alliances that include relationships, such as research, development, collaborative, joint-ventures, and equity alliances, have an inverted $U$-shaped relationship to a biotechnology firm's performance.

\section{Weak tie performance}

Unlike strong ties, weak ties lack the closeness and reciprocity of strong ties (Granovetter, 1973, 1983; McEvily and Zaheer, 1999; Rowley et al., 2000; Uzzi, 1997). Weak ties bridge an organization to non-redundant networks so as to broaden a firm's exposure to novel ideas and resources (see also Burt, 1992; Granovetter, 1973, 1983; Kraatz, 1998; McEvily and Zaheer, 1999; Perry-Smith and Shalley, 2003; Uzzi, 1997). By "bridging" a biotechnology firm to more socially distant members, weak ties gain access to complementary capabilities not internally held by the firm $(\mathrm{Ng}, 2005)$. In that, since distant partners are more likely to possess dissimilar resources, these partners are more likely to possess resources that are complementary to a firm's resources ( $\mathrm{Ng}, 2005)$. Since the commercialization of biotechnology research demands a multitude of complementary production, manufacturing, and distribution assets that no one firm possesses in its entirety (Deeds and Hill, 1996; Powell et al., 1996; Rothaermel, 2001; Rothaermel and Deeds, 2004; Teece, 2000), a weak ties function is to bridge a firm to such distant or complementary resources so as to exploit inter-firm sources of complementary rent. Weak ties should positively influence a firm's performance.

However, similar to strong ties, weak ties are also subject to diminishing return effects. Weak ties reflect armslength or market-like exchange relationships (Rowley et al., 2000; Uzzi, 1997). Weak ties do not involve close and reciprocal exchange relationships and thus do not facilitate the transfer of detailed and tacit knowledge experiences 
(Granovetter, 1973; Uzzi, 1997). Weak ties are, therefore, "one-shot deals" (Uzzi, 1997) and are akin to quasi-market or market-like relationships (Rothaermel, 2001; Rowley et al., 2000; Uzzi, 1997) that include licensing, distribution, and manufacturing related agreements (Chan et al. 1997; Rothaermel and Deeds, 2004; Rowley et al., 2000). In the absence of such reciprocal exchange, weak ties lack trust-based governance (see also Jones et al., 1997). The absence of trust mitigates the equitable distribution of rents. Increasing weak ties, beyond a certain threshold, can expose a biotechnology firm to problems of a "weak appropriability regime" (Teece, 2000). A "weak appropriability regime" occurs when a firm is not able to effectively protect and appropriate inter-firm sources of complementary rent (Teece, 2000). For instance, larger pharmaceutical companies with commercializing assets in distribution, marketing, and manufacturing, can appropriate a disproportionate share of innovation rents from basic research organizations (Teece, 2000). Similarly, basic research start-ups can "hold up" large pharmaceutical companies by requiring them to invest in co-specific commercializing assets. Problems of a weak appropriability regime are particularly acute to weak ties because technological and regulatory uncertainties make it difficult to completely specify all relevant intellectual property rights. Since weak ties are a form of market contract, the uncertainties in the biotechnology industry provide opportunities for partners to disproportionately appropriate inter-firm sources of complementary rents. Furthermore, as weak ties involve the transfer of codified or non-tacit knowledge (i.e., licensing, and marketing, production agreements, etc.), codified knowledge is more difficulty to protect than tacit knowledge and thus exposes a firm to further problems of a weak appropriability regime. As a result, although weak ties provide access to inter-firm complementary rents, further increases in weak ties exposes a firm to problems of a weak appropriability regime. This reduces the performance of weak ties. This diminishing return effect is hypothesized as follows:

Hypothesis 2: Weak tie alliances - quasi-market relationships that include licensing, distribution, marketing, and manufacturing agreements - have an inverted U-shaped relationship to a biotechnology firm's performance.

\section{The balanced performance of strong and weak ties}

As a consequence of the knowledge sharing and commercialization functions of strong and weak ties, strong and weak ties positively - up to a certain threshold - impact a biotechnology firm's performance. This echoes Uzzi's (1997) solution to the "paradox of embeddedness". Uzzi (1997) finds firms that maintain a balance of both strong and weak ties derive the benefits of specialization and flexibility. In the biotechnology industry, strong ties promote a firm's "specialization" in its basic scientific research, while a firm's weak ties exposes it to emerging commercializing opportunities. Hence, from a functional approach, strong and weak ties are distinct yet complementary to a biotechnology firm's performance. Therefore, due to the distinct knowledge sharing and commercializing functions of strong and weak ties, the following is hypothesized:

Hypothesis 3: A biotechnology firm's performance is maximized by having a "balance" of both weak ties and strong ties.

\section{Data and methods}

\section{Data and sample}

A database of publicly traded biotechnology companies in North America for 2003 was constructed from the following data sources: BioScan (American Health Consultants, 2003), Mergent, Sedar, Edgar online, and the U.S. Patent and Trade Office (U.S.P.T.O.). This database contains the cumulative alliances made by 241 North American biotechnology ${ }^{2}$ firms in 2003. As one of the most comprehensive databases on strategic alliances in the biotechnology industry, BioScan has been used by various network researchers (Deeds and Hill, 1996; Powell et al., 1996; Rothaermel, 2001; Rothaermel and Deeds, 2004).

\section{Dependent variable measure: average return on assets (ROA)}

To examine biotechnology performance, a firm's financial data on net income/loss and total assets was collected from Mergent, Sedar and Edgar online databases. A biotechnology firm's Return on assets (ROA) is used as a performance measure. ROA is a commonly accepted measure of performance in management research. Due to the cross sectional nature of this data, a biotechnology firm's ROA is measured by its two year 2002-2003 average. Where financial data was available, a firm's 3 year ROA was used. In addition, as there were some biotechnology firms that had become public in 2003, the 2003 ROA was used.

\section{Independent variables measure: strong ties}

Various alliance studies, especially in the biotechnology industry, have used a firm's cumulative history of alliance agreements as a measure of a firm's connectedness (Chan $e t$ al., 1997; Deeds and Hill, 1996; McEvily and Zaheer, 1999; Rothaermel and Deeds, 2004). A firm's cumulative alliance

2 Biotechnology is used as an umbrella term for both biotechnology and pharmaceutical firms. 
agreements -since a firm's public founding- are found in the 2003 BioScan database. In the BioScan database, agreement types include research, development, collaborative research, joint-ventures, equity, marketing, licensing, and manufacturing arrangements. These categories are consistent with prior network research (Chan et al., 1997; Deeds and Hill, 1996; Rothaermel and Deeds, 2004). The agreements were coded by one researcher and independently verified by another. In drawing on Chan et al. (1997), Deeds and Hill (1996), McEvily and Zaheer (1999), Rothaermel and Deeds, (2004), the cumulative agreement counts for each agreement are used. However unlike these prior studies, the cumulative agreement counts for each agreement type are aggregated in accordance to the dimensions described by the strong and weak tie constructs. This extends the simple alliance counts used in alliance research (e.g. Deeds and Hill, 1996; McEvily and Zaheer, 1999; Rothaermel, 2001; Rothaermel and Deeds, 2004).

For instance, McEvily and Zaheer (1999) measure the strength of network ties - strong and weak ties - by the frequency of alliance counts. They, however, conclude such a measure obscures other important dimensions of relational ties. To capture the notion that strong ties promote the sharing of tacit research knowledge, strong ties consist of the sum of the frequency counts of research (Powell et al., 1996; Rowley et al., 2000), development and collaborative agreements (Deeds and Hill, 1996; Rothaermel and Deeds, 2004; Rowley et al., 2000). These agreement types have been recognized to contain a strong technical and tacit knowledge component (Pisano, 1990). In addition, jointventures and equity ownership positions have also been found to improve a firm's joint problem solving abilities and improve a firm's assimilation of tacit knowledge experiences (Osborn and Hagedoorn, 1997; Uzzi, 1997). As a result, a firm's strong ties consist of the cumulative counts of not only research, development, collaborative agreements, but strong ties also include joint ventures and equity ownership activities. Hence, relative to McEvily and Zaheers' (1999) alliance measure - as well as others (Chan et al., 1997; Deeds and Hill, 1996; Rothaermel and Deeds, 2004) - this study's measure of strong ties incorporates a strong ties' knowledge sharing function.

\section{Independent variables measure: weak ties}

To capture the commercializing function of weak ties, weak ties are one shot deals that consist of quasi-market or nonequity based alliances (Rowley et al., 2000). Weak ties consist of the sum of the cumulative counts of licensing (Chan et al., 1997; Rowley et al., 2000), marketing (Chan et al., 1997; Rowley et al., 2000), manufacturing, and distribution (Chan et al., 1997) agreements. Since these weak ties largely involve the transfer of a firm's biotechnological technical know-how to downstream commercializing partners, these weak ties bridge the firm to the downstream and thus complementary assets of the biotechnology value chain. The squared terms of the strong and weak tie counts are included such that the diminishing effects described in hypotheses 1 and 2 can be tested.

Other measures of the strong and weak tie constructs that may capture the "closeness" or "distance" dimensions of the tie strength construct are S.I.C. (standard industrial classification) based measures. Since strong ties emphasize the "closeness" of exchange relationships, distance measures using S.I.C. classifications can be used to determine a biotechnology firm's proximity to its alliance partners. Biotechnology firms operating in the same or different product market should have similar or dissimilar research backgrounds. Thus, a count of alliance partners that share a firm's S.I.C. classification could be used as a measure of strong ties. Similarly, a count of alliance partners that do not share a firm's S.I.C. classification can be used as a measure of weak ties (see also Miller, 2004). However, as this study emphasizes the reciprocity and tacit dimensions of tie strength, this proposed measure is not used, but could be considered in future research.

\section{Control variables}

To isolate the diminishing effects of strong and weak ties, a biotechnology firm's size, total assets, age and cumulative patents are used as controls. In knowledge-based industries, firm size is defined by the number of its employees (Deeds and Hill, 1996; Rothaermel and Deeds, 2004). Since the assets of a biotechnology firm contain a significant knowledge component, a firm's number of employees is used as a proxy for size. In addition, unlike prior studies (Deeds and Hill, 1996; Rothaermel and Deeds, 2004), this study controlled for a firm's size through its total assets. Due to the cumulative nature of scientific development, age as a proxy for scientific knowledge is expected to be positively related to a firm's financial performance. Firm age is calculated as the difference between the firm's time of founding and the ending period of this data set at 2003. This measure was also used by Rothaermel and Deeds (2004). Lastly, as a firm's cumulative patents can also impact a firm's performance (Rothaermel and Deeds, 2004), this study also controlled for a firm's cumulative patents. Data on a firm's cumulative patents were obtained from the U.S. Patent and Trade Office (U.S.P.T.O.). 


\section{Estimation procedure}

To test hypotheses 1, 2 and 3, the Weighted Least Squares (WLS) method is applied to three econometric models in a step wise fashion. Model I examines the relationship between the control variables and firm performance. In model II, the diminishing return effects of alliances found in Deeds and Hill (1996), Rothaermel and Deeds (2004) are examined. All alliance types are aggregated to form an alliance variable and an alliance ${ }^{2}$ variable is computed to examine the diminishing return effects of alliance performance. This is a procedure used in these prior studies. In model III, alliances are disaggregated in accordance to their strong and weak tie distinctions. The diminishing performance of strong and weak ties is examined in this model.

Models I-III are estimated with the Shazam econometrics software (version 9.0). In estimating these models, tests for heteroscedacity, multicollinearity, and serial autocorrelation are conducted, as their presence can lead to problems of statistical inference and OLS estimates that are not best linear unbiased estimates (BLUE) (Greene, 2000; Wooldridge, 2003). Such problems are commonly found in cross sectional analyses. Heteroscedastic (ARCH test) test indicates the presence of significant heteroscedacity in these models. To correct for heteroscedacity, natural log transformations of the independent variables (linear-log model) were conducted (Greene, 2000; Wooldridge, 2003). In addition, models are also estimated using the Weight
Least Squares (WLS) method whereby the weight is based on the predicted values of ROA. As sources of heteroscedacity are not typically known (Wooldridge, 2003), the weight was determined by the squared predicted values of a firm's ROA. This yielded the greatest model fit. Heteroscedacity (ARCH test) tests on the WLS linear-log models were no longer significant at the $90 \%$ significance level. In addition to correct for multicollinearity, strategic alliance agreements are aggregated in accordance to their strong and weak tie categorizations. The log of strong and weak tie counts is then expressed in quadratic form. This mitigates multicollinearity between the strong and weak tie variables and their squared counterparts (Wooldridge, 2003). Lastly autocorrelation was not significant, as the Durbin-Watson statistic fell in the range of 2.0 for all models. Lastly, given this linearlog model, the log-transformed coefficient estimates are expressed as semi-elasticities. The coefficient estimates measure a unit change in the firm's ROA from a $1 \%$ change in the log- transformed variables

\section{Results and discussions}

The WLS regression results for models I-III are shown in Table 1. Standardized coefficient estimates are reported. In model I, the control variables, age and patents have a positive and significant relationship on a firm's ROA. In using the number of biotechnology products marketed as a dependent variable, Deeds and Hill (1996) and Rothaermel and Deeds (2004) found similar relationships. However

Table 1. WLS Linear-Log Estimation (Dependent variable: Firm ROA).

\begin{tabular}{|c|c|c|c|}
\hline Variables & Model I & Model II & Model III \\
\hline \multicolumn{4}{|c|}{ Control Variables } \\
\hline Employees & $-0.324^{* *}$ & $-0.429^{* * *}$ & $0.459^{* * *}$ \\
\hline Age & $0.417^{* * *}$ & $0.532^{* * *}$ & $0.322^{* * *}$ \\
\hline Total Assets & 0.022 & 0.022 & -0.013 \\
\hline Patents & $0.391^{* * *}$ & $0.694^{* * *}$ & 0.143 \\
\hline \multicolumn{4}{|c|}{ Independent Variables } \\
\hline Alliances & & $6.313^{* * *}$ & \\
\hline Alliances $^{2}$ & & $-5.950^{* *}$ & \\
\hline Strong Ties & & & $9.352^{* * *}$ \\
\hline Strong Ties ${ }^{2}$ & & & $-8.003^{* *}$ \\
\hline Weak Ties & & & $9.681^{* * *}$ \\
\hline Weak Ties ${ }^{2}$ & & & $-8.214^{* * *}$ \\
\hline$D-W$ & 1.963 & 1.971 & 2.018 \\
\hline F-Statistic & $21.237^{* * *}$ & $20.224^{* *}$ & $26.44^{* * *}$ \\
\hline $\mathrm{R}^{2}$ Adj. & 0.252 & 0.325 & 0.459 \\
\hline
\end{tabular}

${ }^{*} p<10 \%,{ }^{* *} p<5 \%,{ }^{* * *} p<1 \%$ 
in our model, the firm's total assets were not significant and employees are negatively related to a firm's financial performance. These relationships are largely maintained through out models II and III.

In model II, the alliance and alliance ${ }^{2}$ estimates show alliances have a positive yet diminishing effect on a firm's ROA. This is consistent with the diminishing effects found in Deeds and Hill (1996) and Rothaermel and Deeds (2004). As these prior studies used a biotechnology firm's number of products marketed as a measure of performance (Deeds and Hill, 1996; Rothaermel and Deeds, 2004), they did not directly determine the effect of alliances on a firm's financial performance. Model II shows the diminishing performance effects of alliances has a direct and significant impact on a firm's ROA.

In model III, alliances are decomposed into their respective strong and weak tie distinctions. Relative to models I and II, this improved the model's fit (i.e. improvement in adjusted $\mathrm{R}^{2}$ ). This suggests that alliance research (e.g. Deeds and Hills, 1996; Rothaermel and Deeds, 2004) should be examined at finer levels of dis-aggregation. In particular, model III shows that both the strong and weak tie coefficient estimates have a positive relationship with a firm's ROA. This finding is in contrast to the argument that strong and weak ties exert opposing influences to a firm's performance. For instance, Rowley et al.'s (2000) findings indicate strong and weak ties have a respective, negative and positive relationship to a firm's ROA. However, in their study, they did not account for the functional distinctions of strong and weak ties. Furthermore, although Reagans and Zuckerman (2001) did not examine the performance of strong and weak ties, they found structural holes and closed networks positively influenced a team's productivity. Since network ties and network structure are highly correlated (e.g. Burt, 2000; Perry-Smith and Shalley, 2003), their findings are compatible with our inter-firm results.

The positive performance of strong and weak ties extends prior empirical studies because these ties have not been examined as analytically distinct constructs. For instance, in studies such as McEvily and Zaheer (1999) and McFadyen and Cannella (2004), strong and weak ties are measured as largely differences in degree. Such a "degree" measure - frequency of exchange - cannot distinguish the knowledge sharing and commercializing functions of strong and weak ties. By accounting for such functional differences, strong and weak ties are not opposing influences on a firm's performance, but appear to mutually reinforce a firm's financial performance.

With respect to hypotheses 1 and 2, the coefficient estimates for the squared terms of the strong and weak ties are negative. This supports the presence of the positive yet diminishing effects of strong and weak ties. Hypotheses
1 and 2 are not rejected. This finding is in contrast to the simple linear relationships found by McEvily and Zaheer (1999), Reagans and Zuckerman (2001) and Rowley et al. (2000). Model III supports the non-linear relationships expressed by McFadyen and Cannella (2004) and Oh et al (2004). Although both studies examined relationships at the interpersonal and project group level of analysis, these studies, respectively, found tie strength and network structure [network closure] exhibited diminishing return effects. Model III's findings not only extend these prior findings to the inter-firm level of analysis, but also provide a direct link to a firm's financial performance, ROA.

In testing for hypothesis 3, the presence of positive yet diminishing returns for both strong and weak ties indicate an optimal network structure that can maximize a firm's performance. From model III, the "optimum" network relatedness is found by calculating the inflexion point (i.e., maximum) for each of the diminishing effects of strong and weak ties. The inflexion point for a quadratic functional form is found by taking the ratio of the strong or weak tie coefficients to twice the coefficient value of their quadratic counterparts (see also Deeds and Hill, 1996; Rothaermel and Deeds, 2004). After conversion to non-log form, the optimum number of strong and weak ties in model III is 1.79 and 1.80 ties, respectively. This suggests an optimal "balance" appears to be an equal number of both strong and weak ties. Hypothesis 3 is not rejected. This finding is consistent with Uzzi's (1997) solution to the "paradox of embeddedness" in which a balance of strong and weak ties derives both the benefits of specialization and flexibility. In the context of the biotechnology industry, these findings indicate an equal "balance" of both strong and weak ties yields a network structure that maximizes a biotechnology firm's research knowledge and commercializing opportunities.

\section{Conclusions}

Although social networks have been widely acknowledged as a source of a firm's competitive advantage and performance, debate continues on the performance of strong and weak ties (Brass et al., 2004). In addressing the conflicting performance of strong and weak ties, this study offers two central conclusions. First and in drawing on Uzzi's (1997) "paradox of embeddedness" and the functional view of networks (Osborn and Hagedorn, 1997), strong and weak ties exhibit distinct knowledge sharing and commercializing functions that jointly and positively impact a biotechnology firm's performance. Second, both strong and weak ties exhibit positive yet diminishing effects to a biotechnology firm's performance. These two conclusions offer three key contributions to social network research 
First, by recognizing the distinct knowledge sharing and commercialization functions of strong and weak ties, strong and weak ties are not opposing influences on a firm's performance. In the biotechnology industry, differences in the degree of reciprocity and closeness of related ties impact a strong and weak ties' knowledge sharing and commercializing functions. These functions in turn yield performance advantages not typically considered in strong and weak tie research (e.g. Gargiulo and Benassi, 2000; Granovetter 1983; Jones et al., 1997; Kraatz, 1998; PerrySmith and Shalley, 2003; Rowley et al., 2000). Although the knowledge sharing and commercializing functions of strong and weak ties may be highly contingent on the conditions of the biotechnology industry, network studies in other industries have reported similar findings. For instance, in Uzzi's (1996) study of the New York apparel industry, he found contractors with either strong or weak ties had a higher failure rate than those contractors that employed a balance of these ties. Strong and weak ties, respectively, serve the functions of increasing a firm's richness of information and flexibility to changing market opportunities (Uzzi, 1997). Simulated studies of network performance $(\mathrm{Ng}, 2004)$ have also found firms with both strong and weak ties exhibited the greatest performance. Furthermore, Reagans and Zuckerman (2001) study in seven industries (i.e. automotive, chemicals, electronics, aerospace, pharmaceuticals, biotechnology and oil) show results that are broadly consistent with our findings.

Second, as strong and weak ties exhibit positive yet diminishing effects; this indicates a more complex explanation of strong and weak tie performance. These diminishing effects not only extends the linear performance arguments of strong ties and weak ties (McEvily and Zaheer, 1999; Perry-Smith and Shalley, 2003; Rowley et al., 2000), but also extends the diminishing return effects observed by Deeds and Hill (1996), and Rothaermel and Deeds (2004). This study not only reinforced Deeds and Hill (1996) and Rothaermel and Deeds (2004) earlier findings (i.e. model II), but also found strong and weak ties exhibited similar diminishing return effects (i.e. model III). This has two implications. First, such diminishing effects indicate strategic alliances should be examined at further levels of dissaggregation. Second, although limits on a firm's rationality have a significant bearing on these diminishing effects (Rothaermel and Deeds, 2004); the diminishing effects of strong and weak ties may be unique to their respective functions. For instance, as strong ties promote the sharing of tacit knowledge, they lead to an increasing co-specialization of assets. This increases problems of holdup or abuses of trust that can eventually reduce a strong tie's performance. Furthermore, as a weak tie's function is to commercialize a firm's basic research knowledge, weak ties tend to transmit more codified sources of knowledge which can increasingly expose a firm to conditions of a "weak appropriability regime" (Teece, 2000). As a result, differences in a tie strength's knowledge sharing and commercializing functions can expose a firm to increasing abuses of trust (i.e. strong ties) and an inability to fully appropriate inter-firm sources of complementary rents (i.e. weak ties). These problems of network governance have not been examined by Deeds and Hill (1996) and Rothaermel and Deeds (2004).

Third, support for such diminishing effects also provides direct support for Uzzi's (1997) contention that a balance of both strong and weak ties can be a solution to the paradox of embeddedness. In that, due to the presence of such diminishing effects, moderation in the use of both strong and weak ties is favored over the exclusive reliance on either tie. This suggests a network structure consisting of an equal balance of both strong and weak ties yields the greatest financial performance. This has significant implications to the management of network relationships. Since maintaining and developing social ties are costly and cognitively demanding (McFadyen and Cannella, 2004), this result suggests that maintaining such a balance of ties can conserve a firm's limited managerial resources.

These contributions, however, need to be tempered by this study's limitations. First, although this study subscribes to a contingency approach to social network research (e.g. Rowley et al., 2000), the robustness of our strong and weak tie findings require replication in other industries. Furthermore, even with in the biotechnology industry, our strong and weak tie findings may require further replication at later periods of industry development. The biotechnology industry has undergone considerable growth and increased maturity. The commercialization of basic research has become an important priority for biotechnology firms. Hence, the optimal network structure may evolve from an equal balance of strong and weak ties towards a balance of ties that favors the commercializing functions of weak ties. As a result, strong and weak tie performance may be contingent on the specific stage of this industry's life cycle development. Future studies should examine this balance of strong and weak ties at later periods of biotechnology industry development. Second, this study provides an initial attempt to integrate network governance explanations (i.e. abuses of trust and weak appropriability regime) to explaining the diminishing effects of strong and weak ties. Although our results are consistent with these arguments, our results are largely exploratory in nature. Future studies would require incorporating measures that reflect conditions of co-asset specificity, "weak appropriability", and hold up (i.e. abuses of trust). Third, social network research is largely pre-occupied with the dimensions of 
network structure without explicit consideration of the nodes that connect them (Brass et al., 2004). Hence, such a focus tends to omit consideration of the casual mechanisms as well as intervening variables that impact the formation and performance of strong and weak ties. For instance, a firm's absorptive capacity (e.g. Cohen and Levinthal, 1990; Lane and Lubatkin, 1998) has been recognized to impact its ability to relate to external information. Thus, a firm's absorptive capacity could impact the formation of strong and weak ties. This is because a firm's ability to interpret the information of its strong and weak ties is dependent on its prior experiences. With respect to performance, although there is significant research that supports the positive effects of social networks on firm performance (Brass et al., 2004), firm level factors also impact performance. Although this study has controlled for firm level factors, it has not controlled for other factors. For instance, in Danneels (2002) and Dutta et al.'s (1999) study of firm product innovation, firms with both a strong technical knowledge base and marketing competence increased their ability to introduce new product innovations. In the pharmaceutical industry, Nerkar and Roberts (2004) found evidence that pharmaceutical firms with both research and productmarket experiences jointly improved a firm's performance. In addition, a firm's status or reputation has also been related to the performance of embedded relationships (Podolyn, 1994). As a result, a direction for future research is to integrate a firm's absorptive capacity and status into the examination of the formation and performance of strong and weak ties.

\section{References}

American Health Consultants, 2003. BioScan Database.

Brass, D.J., J. Galaskiewicz, H.R. Greve and W. Tsai, 2004. Taking stock of networks and organizations: a multilevel perspective. Academy of Management Journal, 47(6), 795-817.

Burt, R.S., 1992. Structural Holes: The Social Structure of Competition. Harvard University Press: Cambridge MA.

Burt, R.S., 1997. The contingent value of social capital. Administrative Science Quarterly, 42 (2), 339-365.

Burt, R.S., 2000. The network structure of social capital. In B.M. Staw and R.I. Sutton (Eds.), Research in organizational behavior: An annual series of analytical essays and critical reviews: Vol. 22, Elsevier Science: New York, 345-423.

Chan, S.H., J.W. Kensinger, A.J. Keown and J.D. Martin, 1997. Do strategic alliances create value? Journal of Financial Economics, 46: 199-221.

Cohen, W.M. and D.A. Levinthal, 1990. Absorptive Capacity: a New Perspective on Learning And Innovation. Administrative Sciences Quarterly, 35, 128-152.
Coleman, J.S., 1988. Social capital in the creation of human capital. American Journal of Sociology, 84, 95-120.

Danneels, E., 2002. The dynamics of product innovation and firm competences. Strategic Management Journal, 23, 1095-1121.

Deeds, D.L. and C. Hill, 1996. Strategic alliances and the rate of new product development: an empirical study of entrepreneurial biotechnology firms. Journal of Business Venturing, 11, 41-55.

Dutta, S., O. Narasimhan and S. Rajiv, 1999. Success in hightechnology markets: is marketing capability critical? Marketing Science, 18 (4), 547-568.

Dyer, J. and K. Nobeoka, 2000. Creating and managing a high performance knowledge-sharing network: the Toyota case. Strategic Management Journal, 21, 345-367.

Gargiulo, M. and M. Benassi, 2000. Trapped in your own net? network cohesion, structural holes, and the adaptation of social capital. Organization Science, 11 (2), 183-196.

Granovetter, M., 1973.The strength of weak ties. American Journal of Sociology, 78 (6), 1360-1380.

Granovetter, M., 1983. The strength of weak ties: a network theory revisited. Sociological Theory, 1, 201-233.

Granovetter, M., 1985. Economic action and social structure: the problem of embeddedness. American Journal of Sociology, 91(3), 481-510.

Greene, W.H., 2000.Econometric Analysis: $4^{\text {th }}$ Edition. Upper Saddle River NJ: Prentice Hall.

Jones, C., W.S. Hesterly and S.P. Borgatti, 1997. A general theory of network governance: exchange conditions and social mechanisms. Academy of Management Review, 22(4), 911-945.

Kraatz, M., 1998. Learning by association? interorganizational networks and adaptation to environmental change. Academy of Management Journal, 41(6), 621-643.

Lane, P.J. and M. Lubatkin, 1998. Relative absorptive capacity and interorganizational learning. Strategic Management Journal, 19, 461-477.

Liebeskind, J.P., A. Oliver, L. Zucker and M. Brewer, 1996. Social networks, learning, and flexibility: sourcing scientific knowledge in new biotechnology firms. Organization Science, 7(4), 428443.

McEvily, S.K. and Zaheer, 1999. Bridging ties: a source of firm heterogeneity in competitive capabilities. Strategic Management Journal, 20, 1133-1156.

McFadyen, M.A. and A.A. Cannella, 2004. Social capital and knowledge creation: diminishing returns of the number and strength of exchange relationships. Academy of Management Journal, 47(5), 735-747.

Miller, D.J., 2004. Firm's technological resources and the performance effects of diversification: a longitudinal study. Strategic Management Journal, 25, 1097-1119.

Ng, D. 2004., The social dynamics of diverse and closed Networks. Human Systems Management, 23, 111-122. 
Ng, D. 2005., The Discovery of and Coordination of Resource Complements in a Dispersed Knowledge Society. Int. J. Human Resource Development and Management, 5 (2), 142-163.

Nerkar, A. and P.W. Roberts, 2004. Technological and productmarket experience and the success of new product introductions in the pharmaceutical Industry. Strategic Management Journal, 25, 779-799.

Oh, H., M. Chung and G. Labianca, 2004. Group social capital and group effectiveness: the role of informal socializing ties. Academy of Management Journal, 47 (6), 860-875.

Osborn, R.N. and J. Hagedoorn, 1997. The institutionalization and evolutionary dynamics of interorganizational alliances and networks. Academy of Management Journal, 40 (2), 261-278.

Perry-Smith, J.E. and C.E. Shalley, 2003.The social side of creativity: a static and dynamic social network perspective. Academy of Management Review, 28 (1), 89-107.

Pisano, G., 1990. The R\&D boundaries of the firm: an empirical analysis. Administrative Science Quarterly, 35 (1), 153-176.

Podolny, J.M., 1994. Market uncertainty and the social character of economic exchange. Administrative Science Quarterly, 39, 458-483.

Powell, W.W., K.W. Koput and L. Smith-Doerr, 1996. Interorganizational Collaboration and the locus of innovation: networks of learning in biotechnology. Administrative Science Quarterly, 41, 116-145.

Reagans, R. and E.W. Zuckerman, 2001. Network, diversity, and productivity: the social capital of corporate R\&D teams. Organization Science, 12 (4), 502-517.

Rothaermel, FT., 2001. Complementary assets, strategic alliances, and the incumbent's advantage: an empirical study of industry and firm effects in the biopharmaceutical industry. Research Policy, 30, 1235-1251.

Rothaermel, F.T. and D.L. Deeds, 2004. Exploration and exploitation alliances in Biotechnology: a system of new product development. Strategic Management Journal, 25, 201-221.

Rowley, T., D. Behrens and D. Krackhardt, 2000. Redundant governance structures: an Analysis of structural and relational embeddedness in the steel and semiconductor industries. Strategic Management Journal, 21, 369-386.

Sporleder, T. and L. Moss, 2002. Knowledge management in global food system: network embeddedness and social capital. American Journal of Agricultural Economics, 84 (2), 1345-1352.

Teece, D.J., 2000. Managing Intellectual Capital. Oxford: Oxford University Press.

Uzzi, B., 1996. The sources and consequences of embeddedness for the economic performance of organizations. American Sociological Review, 61, 674-698.

Uzzi, B., 1997. Social structure and competition in interfirm networks: the paradox of embeddedness. Administrative Science Quarterly, 42 (1), 35-67.
Wooldridge, J.M., 2003. Introductory Econometrics: A Modern Approach $2^{\text {nd }}$ Edition. Manson $\mathrm{OH}$ : South Western College Publishing. 